điều trị thất bại cao gấp 5,53 lần (95\%CI:2,85$19,72)[6]$. Thực tế kinh tế khó khăn, thu nhập bi mất trong quá trình điều trị lao kéo dài và việc nhờn thuốc do đã từng điều trị lao trước đó ảnh hưởng đến quá trình điêu trị lao.

Các nghiên cứu trước cho thấy có mối liên quan giứa $\operatorname{HIV}(+), A F B(+)$ [4], [6], tác dụng không mong muốn nặng của thuốc [3] có liên quan đến kết quả điều trị RR-TB. Bênh nhân có bệnh đồng mắc, $\operatorname{HIV}(+)$ thì kết quả điều trị không thành công sẽ cao hơn, điều này hoàn toàn phù hợp với y văn. Thực tế, nếu phải điều trị kéo dài, gây tốn kém, mất thời gian, mêtt mỏi và bi ảnh hưởng của thuốc thì sẽ ảnh hưởng đến tâm lý của bệnh nhân, làm cho bệnh nhân có xu hướng bỏ trị hoặc không tuân thủ điều trị, qua đó ảnh hưởng kết quả điều trị. Nghiên cứu của chúng tôi phù hợp với y văn và phù hợp với các nghiên cứu trước khi cho kết quả: có mối liên quan có ý nghĩa thống kê giữa mắc bệnh kèm theo, $\operatorname{HIV}(+)$, $\mathrm{AFB}(+)$, chế độ điều trị 20 tháng, bệnh nhân tại trại giam, không tuân thủ xét nghiệm và gặp tác dụng không mong muốn với kết quả điều trị RRTB không thành công $(p<0,05)$.

\section{KẾT LUẬN}

Tuổi trung bình của bệnh nhân RR-TB là $40,9 \pm 12,3$, tỉ lệ nam $79,3 \%$. Tỉ lệ có tiền sử điều trị lao $73,9 \%$, lao mới $26,1 \%$ và $\operatorname{HIV}(+) 19,6 \%$. Tỉ lệ lao tại phổi 97,8\%; thể AFB(+) 72,8\%. Tỉ lệ tuân thủ xét nghiệm trong quá trình theo dõi điều trị $28,3 \%$. Tỉ lệ điêuu trị khỏi $3,5 \%$, hoàn thành điều trị $75,5 \%$, tử vong $10,5 \%$, thất bại $2,3 \%$, bỏ trị $7,0 \%$, chuyển $1,2 \%$. Có mối liên quan giữa tình trạng kinh tế hộ gia đình nghèo, tiên sử lao, mắc bệnh kèm theo, $\operatorname{HIV}(+)$, $\mathrm{AFB}(+)$, thời gian điều trị 20 tháng, bệnh nhân tại trại giam, không tuân thủ xét nghiệm và gặp tác dụng không mong muốn với kết quả điều trị RR-TB không thành công $(p<0,05)$.

\section{TÀI LIÊU THAM KHẢO}

1. Chương trình chống lao quốc gia (2021), Báo cáo tổng kết chương trình chống lao năm 2020, Bộ Y tế, Hà Nội.

2. Bô Y tế (2020), Câp nhât hướng dẫn chẩn đoán điều trị và dự phòng bệnh lao, Nhà xuất bản $Y$ học, Hà Nội.

3. Bulabula A.N.H., Nelson J.A., Musafiri E.M., et al. (2019), "Prevalence, Predictors, and Successful Treatment Outcomes of Xpert MTB/RIFidentified Rifampicin-resistant Tuberculosis in Postconflict Eastern Democratic Republic of the Congo 2012-2017: A Retrospective Province-Wide Cohort Study", Clinical infectious diseases: an official publication of the Infectious Diseases Society of America, 69 (8), pp. 1278-1287.

4. Katende B., Esterhuizen T.M., Dippenaar A., et al. (2020), "Rifampicin Resistant Tuberculosis in Lesotho: Diagnosis, Treatment Initiation and Outcomes", Sci Rep, 10 (1), pp. 1917.

5. Phuong N.T.M., Nhung N.V., Hoa N.B., et al. (2016), "Management and treatment outcomes of patients enrolled in MDR-TB treatment in Viet Nam", Public health action, 6 (1), pp. 25-31.

6. Van Le Hong, Phu Phan Trieu, Vinh Dao Nguyen, et al. (2020), "Risk factors for poor treatment outcomes of 2266 multidrug-resistant tuberculosis cases in Ho Chi Minh City: a retrospective study", BMC Infectious Diseases, 20 (1), pp. 164

7. World Health Organization (2020), Global tuberculosis report 2020, World Health Organization, Geneva, Switzerland.

\title{
ĐĂC ĐIỂM TỔN THƯƠNG VÕNG MAC TRÊN BỆNH NHÂN ĐÁI THÁO ĐƯỜNG TẠI BỆNH VIỆN ĐA KHOA KHU VỰC PHÚC YÊN
}

\section{TÓM TẮT}

Mục tiêu: 1, Mô tả đặc điểm lâm sàng của tổn thương võng mạc trên bệnh nhân bị bệnh đái tháo đường (ĐTĐ) tại Bệnh viện đa khoa khu vực Phúc Yên. 2, Nhận xét một số yếu tố liên quan đến bệnh võng mạc đái tháo đường trên nhóm bệnh nhân

${ }^{1}$ Bệnh viên Măt trung ương

2Bêenh viện đa khoa Phúc Yên

Chịu trách nhiệm chính: Vũ Tuấn Anh

Email: vta.oph@gmail.com

Ngày nhận bài: 3.3.2021

Ngày phản biên khoa hoc: 26.4.2021

Ngày duyệt bài: 7.5.2021

\section{Vũ Tuấn Anh', Nguyễn Thị Ngọc Hân²} nghiên cứu. Đối tượng và phương pháp nghiên cứu: nghiên cưú mô tả cắt ngang trên 273 bệnh nhân ĐTÐ (546 mắt), thu thập các thông tin cơ bản (tuổi, giới, thời gian mắt ĐTĐ, typ ĐTÐ...), khám đáy mắt và chup mach huỳnh quang xác đinh tổn thương và giai đoạn bệnh võng mạc ĐTÐ. Kết quả: tuổi bệnh nhân trung bình $61,6 \pm 11,8$ (17-89); thi lức giảm vừa chiếm chủ yếu $50 \%$ (273/546); tỷ lệ mắc bệnh võng mac ĐTÐ chiếm 25,5\% (139/546 mắt), trong đó giai đoạn chưa tăng sinh nhẹ là $21,2 \%$ (113 mắt), chưa tăng sinh vừa $0,9 \%$ (5 mắt), chưa tăng sinh nặng $0,7 \%$ (4 mắt) và tăng sinh $2,7 \%$ (15 mắt), tỷ lẹ phù hoàng điểm $6 \%$ (33 mắt); có mối liên quan chặt chẽ giữa bệnh võng mạc ĐTÐ với thời gian mắc bênh ĐTÐ $(p<0,001)$, với kiểm soát tốt đường máu $(\mathrm{H} \dot{\mathrm{b} A} 1 \mathrm{c}<7)$ 
( $p<0,05 \%)$. Kết luận: tỷ lệ mắc bệnh võng mạc ĐTĐ trên quần thể bênh nhân ĐTंĐ ở địa phương đáng chú ý, vì vậy việc khám sàng lọc định kỳ võng mạc trên bệnh nhân Đ̇TĐ là hết sức cần thiết.

Tư khóa: bệnh võng mạc đái tháo đường, bệnh đái tháo đường

\section{SUMMARY \\ RETINAL LESION FEATURES OF DIABETES PATIENTS IN PHUCYEN HOSPITAL}

Purpose: 1, Descibe the retinal features of diabetes patients in Phucyen hospital 2, Investigate some findings diabetic retinopathy- related in diabetes patients. Materials and Methods: coss-sectional study, 546 eyes of 273 diabetes, grading for retina lesion (R0 $\rightarrow \mathrm{R} 4)$, macular lesion (M0, M1) following the criteria of the ICO classification. Results: demography: age average $61,7 \pm 11.8$ (17-89) majority of eyes has mild vision impairment (50\%); DR prevalence is $25.5 \%$ included R1 $21.2 \%$, R2 $0.9 \%$, R3 $0.7 \%$, R4 $2.7 \%$ and macular edema (M1) prevalence is $6 \%$; DR has significant relationship with longer duration of DM $(p<0,001)$, with tight glycaemia control $(\mathrm{HbA} 1 \mathrm{c}<7)(\mathrm{p}<0,05)$. Conclusion: prevalence of DR in DM group was remarkable, so the DR screening in provincial level would be necessary.

Keyword: diabetic retinopathy, diabetes mellitus

\section{I. ĐĂT VẤN ĐỀ}

Bệnh võng mạc do đái tháo đường đang dần trở thành nguyên nhân gây mù lòa chính ở các nước đang phát triển, trong đó có Việt Nam ${ }^{1,2}$. Bệnh lý này là gánh nặng cộng thêm của bệnh ĐTÐ về mặt kinh tế-xã hội ${ }^{3}$. Việc nghiên cứu bệnh lý này ở các đơn vị y tế đa khoa tuyến tỉnh là rất cần thiết, nhằm góp phần đưa ra các quyết sách đúng đắn trong việc xây dựng hệ thống theo dõi, sàng lọc và quản lý bệnh võng mạc ĐTÐ trên toàn quốc. Vì vậy, chúng tôi tiến hành nghiên cứu này mục tiêu:

1. Mô tả đặc điểm lâm sàng của tổn thương võng mạc trên bệnh nhân bi bệnh đái tháo đường tại Bệnh viện đa khoa khu vực Phúc Yên.

2. Nhận xét một số yếu tố liên quan đến bệnh võng mạc đái tháo đường trên nhóm bệnh nhân nghiên cứu.

\section{II. ĐỐI TƯợNG VÀ PHƯƠNG PHÁP NGHIÊN CỨU}

2.1. Đối tượng nghiên cứu. Các bệnh nhân đã được chẩn đoán ĐTĐ đến khám và điều trị tại Bệnh viện ĐKKV Phúc Yên từ 09/2016 đến 08/2017.

Tiêu chuẩn lựa chọn bệnh nhân: là tất cả những bệnh nhân đã được chẩn đoán xác định ĐTÐ đồng ý tham gia nghiên cứu.

Tiêu chuẩn loại trừ: bệnh nhân quá già yếu, khó hợp tác; bệnh nhân dị ứng hoặc nghi ngờ dị ứng với fluorescein; bệnh nhân bị đục nhiều môi trường trong suốt của mắt ở mức độ cản trở soi đáy mắt (sẹo giác mạc, đục thủy tinh thể), khó giãn đồng tử.

\subsection{Thiết kế và qui trình nghiên cứu}

Nghiên cứu mô tả cắt ngang,

Thu thập các thông tin cơ bản: tuổi, giới, typ ĐTÐ, thời gian mắc bệnh ĐTÐ

Khám măt: Thử thị lực có chỉnh kính với bảng thị lực Snellen

Đánh giá phân loại thị lực theo quy định của Tổ chức y tế thế giới (WHO) năm 1985.

- Khám bán phần trước thường quy

- Khám phát hiện tổn thương bán phần sau: sau khi nhỏ giãn đồng tử tối đa k, hám đáy mắt bằng kính Volk +90D kết hợp với sinh hiển vi khám bệnh phát hiện các tổn thương võng mạc

- Chup mạch huỳnh quang fluorescein $20 \%$ khi có tổn thương võng mạc

- Xác đinh giai đoan bênh võng mạc ĐTÐ

\begin{tabular}{|c|c|}
\hline Không mắc bệnh & R0 \\
\hline Không tăng sinh - nhẹ & R1 \\
\hline Không tăng sinh - vừa & R2 \\
\hline Không tăng sinh - nặng & R3 \\
\hline Tăng sinh & R4 \\
\hline Phù hoàng điếm/không phù & M1 / M0 \\
\hline
\end{tabular}

Khám toàn thân: huyết áp, đường máu, HbA1c, lipid máu, creatinin máu.

Đạo đức nghiên cứu: Nghiên cứu tuân thủ các qui tắc đạo đức trong nghiên cứu $Y$ sinh học, được thông qua Hội đồng đạo đức và được mã hóa, giữ bí mật thông tin của bệnh nhân.

\section{KẾT QUẢ NGHIÊN CỨU VÀ BÀN LUÂ̂N}

Trong thời gian nghiên cứu từ tháng 9/2016 đến $8 / 2017$, chúng tôi tiến hành nghiên cứu, thu nhập số liệu và khám 546 mắt của 273 bệnh nhân.

\section{1. Đắc điểm của bệnh nhân.}

3.1.1. Tuổi, giới và typ ĐTĐ. Tỷ lệ bệnh nhân nam chiếm 53,5\%, bệnh nhân nữ chiếm 46,5\%.

Trong số 273 bệnh nhân nghiên cứu có 8 bênh nhân bị ĐT $Đ$ type I, chiếm 2,9\%. Còn lại 265 bệnh nhân bị ĐT Đ type II, chiếm 97,1\%.

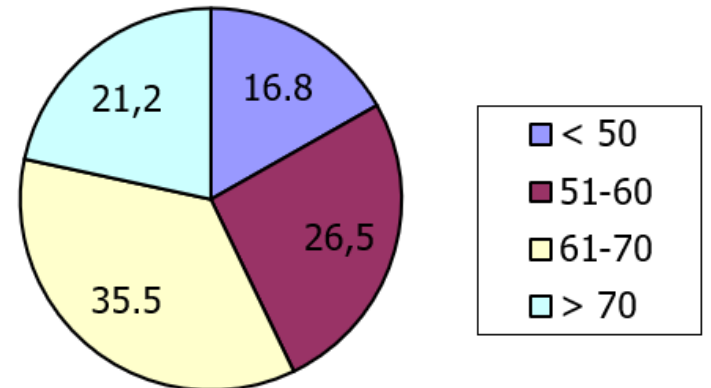

Biểu đồ 3.2. Phân bố bệh nhân theo nhóm tuổi Tuổi trung bình của nhóm đối tượng nghiên 
cứu là $61,7 \pm 9,4$ (17-89). Tỷ lệ bệnh nhân gặp nhiều nhất là những người trong độ tuổi từ 5070 tuổi, chiếm tới $60 \%$. Tỷ lệ bệnh nhân trong độ tuổi dưới 50 tuổi gặp ít nhất, chiếm 16,8\%. Nhóm bệnh nhân trên 70 tuổi chiếm tỷ lệ 21,2\%. Tỷ lệ bệnh nhân trong độ tuổi dưới 60 là 43,3\%.

Bảng 3.1. Phân bố tổn thương vông mạc theo tuổi

\begin{tabular}{|c|c|c|c|c|c|c|}
\hline \multirow{2}{*}{ Tuổi Tổn thương } & \multicolumn{2}{|c|}{$\begin{array}{c}\text { Không mắc } \\
(n=193)\end{array}$} & \multicolumn{2}{|c|}{$\begin{array}{c}\text { Có bệnh VM ĐTÐ } \\
(n=80)\end{array}$} & \multirow{2}{*}{$\begin{array}{l}\text { Tỷ lệ theo } \\
\text { tuổi }\end{array}$} & \multirow{2}{*}{ p } \\
\hline & SL & $\%$ & SL & $\%$ & & \\
\hline$\leq 50$ & 33 & 17,1 & 13 & 16,25 & 16,8 & \multirow{4}{*}{$<0,05$} \\
\hline $51-60$ & 55 & 28,5 & 17 & 21,25 & 26,4 & \\
\hline $61-70$ & 67 & 34,7 & 30 & 37,5 & 35,5 & \\
\hline$>70$ & 38 & 19,7 & 20 & 25 & 21,3 & \\
\hline Tống & 193 & 100 & 80 & 100 & 100 & \\
\hline
\end{tabular}

Trong số 80 bệnh nhân có bệnh võng mạc ĐTÐ, tỷ lệ bệnh nhân gặp nhiều nhất là ở độ tuổi $61-70$ tuổi chiếm 37,5\%, bệnh nhân ở đồ tuổi $51-60$ và > 70 tuổi gặp với tỷ lệ $21,25 \%$ và $25 \%$, gặp ít nhất là ở độ tuổi < 50 tuổi với tỷ lệ 16,25\%. Trong số 193 bệnh nhân không mắc bệnh võng mạc $Đ T \bigoplus$, độ tuổi gặp nhiều nhất là từ 51-70 tuổi, nhóm có độ tuổi $<50$ và $>70$ tuổi gặp với tỷ lệ $17,1 \%$ và $19,7 \%$. Khác biệt có ý nghĩa thống kề với $p<0,05$.

Đặc điểm về tuổi của nhóm đối tượng nghiên cứu của chúng tôi tương đương với nhóm đối tượng nghiên cứu của tác giả Hoàng Thị Phúc ${ }^{6}$, với tỷ lệ bệnh nhân dưới 60 tuổi là 45,4\%. Còn so với nhóm đối tượng nghiên cứu của tác giả Trần Minh Tiến ${ }^{5}$, nhóm độ tuổi này của chúng tôi lại thấp hơn hẳn, với tỷ lệ mà tác giả này đưa ra là $62,1 \%$. Chúng tôi nhận thấy rằng có thể do số bệnh nhân lớn tuổi, bệnh nặng nên được chuyển đến điều trị tại bệnh viện tuyến trung ương.

Bênhh đã trở thành một gánh nặng về mặt kinh tế -xã hội. Nhận định này cũng tương ứng với nhiều tác giả trên thế giới cũng như ở Việt $\mathrm{Nam}^{1,2,4}$.

\subsection{Thời gian mắc bệnh đái tháo đường} Bảng 3.2. Thời gian mắc ĐTÐ

\begin{tabular}{|c|c|c|}
\hline Thời gian & Số lượng & Tỷ lệ (\%) \\
\hline$\leq 5$ năm & 160 & 58,6 \\
\hline $5-\leq 10$ năm & 77 & 28,2 \\
\hline $10-\leq 15$ năm & 19 & 7,0 \\
\hline$>15$ năm & 17 & 6,2 \\
\hline
\end{tabular}

Bệnh nhân mắc ĐTĐ dưới 5 năm chiếm tỷ lệ cao nhất là $58,6 \%$. Sau đó là nhóm bệnh nhân mắc bệnh từ 5-10 năm chiếm 28,2\%. 2 nhóm mắc bểnh từ $10-15$ năm và trên 15 năm chiếm $7,0 \%$ và $6,2 \%$. Thời gian mắc bệnh trung bình là $5,8 \pm 4,9$ năm. Kết quả cho thấy phần lớn bệnh nhân trong nhóm nghiên cứu của chúng tôi có thời gian phát hiện bệnh sớm. Kết quả nghiên cứu của tác giả Trần Minh Tiến ${ }^{5}$, nhóm đối tượng nghiên cứu có thời gian phát hiện bệnh dưới 5 năm là $35,8 \%$, từ $5-10$ năm là $34,3 \%$, và trên 10 năm là $30 \%$. So với tác giả này, tỷ lệ bệnh nhân phát hiện bệnh dưới 5 năm của chúng tồi là cao hơn, nhưng nhóm phát hiện bệnh trên 10 năm lại thấp hơn nhiều. Có thể do tác giả này nghiên cứu những đối tượng đang điều trị tại các bệnh viện Mắt Trung Ương, Nội Tiết Trung Ương, Bạch Mai, là những bệnh viện tuyến trung ương, bệnh nhân đến điêu trị thường là những bệnh nhân mắc bệnh lâu năm, bệnh nặng, có biến chứng nặng, điều trị tại tuyển tỉnh không hiệu quả phải chuyển lên hoặc bệnh nhân tự lên điểu trị do bị bệnh kéo dài.

3.2. Đặc điểm bệnh võng mạc đái tháo đường và 1 số yếu tố liên quan

3.2.1. Phân bố tỷ lệ bệnh võng mạc ĐTĐ tính theo số mắt

Bảng 3.3. Giai đoạn bệnh võng mạc ĐTÐ tính theo số mắt

\begin{tabular}{|c|c|c|}
\hline Tổn thương võng mạc & $\begin{array}{c}\text { Số } \\
\text { mắt }\end{array}$ & $\begin{array}{c}\text { Tỷ lề } \\
(\%)\end{array}$ \\
\hline Không có bệnh VM ĐTĐ & 407 & 74,5 \\
\hline Giai đoạn nền (R1-R2) & 120 & 22 \\
\hline Tiền tăng sinh (R3) & 4 & 0,7 \\
\hline Tăng sinh (R4) & 15 & 2,8 \\
\hline Tống & $\mathbf{5 4 6}$ & $\mathbf{1 0 0}$ \\
\hline
\end{tabular}

Trên 546 mắt của 273 bệnh nhân nghiên cứu có 139 mắt đã có bệnh võng mạc ĐTÐ chiếm $25,5 \%$. Trong đó có 120 mắt bệnh võng mạc ĐTĐ giai đoạn nền chiểm tỷ lệ $22 \%$, có 4 mắt bị bệnh võng mạc ĐTĐ giai đoạn tiền tăng sinh, chiếm tỷ lệ $0,7 \% .15$ mắt bị bệnh võng mạc ĐTÐ giai đoạn tăng sinh chiếm 2,8\%. Còn lại 407 mắt chưa mắc bệnh võng mạc ĐTĐ chiếm tỷ lệ $74,5 \%$. Ngoài ra, còn có 33 mắt $(6 \%)$ có phù hoàng điểm (M1), gặp rải rác ở tất cả các giai đoạn của bệnh võng mạc ĐTĐ. 
Bảng 3.3a. Tỷ lệ giai đoạn vông mạc ĐTÐ của một số nghiên cứu

\begin{tabular}{|c|c|c|c|c|}
\hline Tác giả & $\begin{array}{c}\text { Chưa tăng } \\
\text { sinh nhę(\%) }\end{array}$ & $\begin{array}{c}\text { Chưa tăng sinh } \\
\text { vừa(\%) }\end{array}$ & $\begin{array}{c}\text { Chưa tăng sinh } \\
\text { nặng (\%) }\end{array}$ & $\begin{array}{c}\text { Tăng } \\
\sinh (\%)\end{array}$ \\
\hline Trần M & 18,6 & 16,5 & 28,8 & 36,1 \\
\hline Nguyền Thế Vinh77 & 23,5 & 32,5 & 28,4 & 15,7 \\
\hline Nhóm nghiên cứu & 81,3 & 3,6 & 1,4 & 10,8 \\
\hline
\end{tabular}

So với 2 tác giả trên, tỷ lệ bệnh nhân có bệnh võng mạc chưa tăng sinh mức độ nhẹ trong nghiên cứu của chúng tôi cao hơn nhiêu. Trong khi ở các mức độ nặng hơn lại thấp hơn nhiêu. Có thể là do thời gian mắc bệnh ĐTĐ trong nhóm nghiên cứu của chúng tôi thấp hơn. Mặt khác, 2 tác giả trên nghiên cứu trên những đối tượng đang điều trị tại các bệnh viện tuyến trung ương, thường là những bệnh nhân mắc

bê̂nh nặng, đã có nhiều biến chứng do ĐTĐ, điều trị tại các tuyến cơ sở không đáp ứng nên được chuyển lên tuyến trên. Do đó tỷ lệ bệnh nhẩn giai đoạn tăng sinh nặng trong nghiên cứu của các tác giả đó cao hơn của chúng tôi. Tỷ lệ bệnh đe dọa thị lực (R3,R4) là $12,2 \%$, gần xấp xî̀ so với công bố trên thế giới ${ }^{1}$, trong khi tỷ lệ phù hoàng điểm có thấp hơn so với các nghiên cứu trước đó2,3,4 (vào khoảng $6 \%$ so với $10 \%)^{1,2}$

\subsubsection{Phân bố mức độ tổn hại thị lực}

Bảng 3.4. Mối liên quan giứa tình trạng thị lực và tổn thương vông mạc

\begin{tabular}{|c|c|c|c|c|c|c|c|}
\hline Tốn thương & \multicolumn{2}{|c|}{ Không TT $(n=407)$} & \multicolumn{2}{|c|}{ Chưa TS $(n=124)$} & \multicolumn{2}{|c|}{ Tăng sinh $(n=15)$} & \multirow[b]{2}{*}{$\mathbf{p}$} \\
\hline Thị lực & $\mathbf{S L}$ & $\%$ & SL & $\%$ & SL & $\%$ & \\
\hline$>20 / 30$ & 78 & 19,2 & 6 & 4,8 & 0 & 0 & \\
\hline $20 / 60-20 / 30$ & 216 & 53,1 & 57 & 46 & 0 & 0 & $<$ \\
\hline ENT $3 m-20 / 60$ & 97 & 23,8 & 50 & 40,3 & 3 & 20,0 & 0,05 \\
\hline$<$ ĐNT $3 \mathrm{~m}$ & 16 & 3,9 & 11 & 8,9 & 12 & 80,0 & \\
\hline
\end{tabular}

Trong số 407 mắt không có bệnh, tỷ lệ mắt có thị lực trên $20 / 60$ chiếm đa số với tỷ lệ $72,3 \%$. Nhóm có tổn thương võng mạc ĐTĐ chưa tăng sinh tỷ lệ gặp nhiều nhất là nhóm có thị lực từ ĐNT3m-20/30. Tuy nhiên ở nhóm có tổn thương ở giai đoạn tăng sinh, tất cả các mắt đều có thị lực dưới 20/60, và tỳ lệ cao nhất là nhóm có thị lực dưới ĐNT3m, chiếm tới $80 \%$. Có mối liên quan chặt chẽ giữa thị lực và tình trạng

tổn thương võng mạc với $p<0,05$.

Tác giả Trần Minh Tiến cũng đưa ra nhận xét, tỷ lệ bệnh nhân có thị lực kém tăng ở nhóm bệnh nhân có phù hoàng điểm ${ }^{5}$. Nghiên cứu của chúng tôi không chỉ đánh giá trên tổn thương phù hoàng điểm mà còn đánh giá trên tất cả các hình thái tổn thương võng mạc. Vì vậy, hạn chế của nghiên cứu này là chưa chỉ rõ được nguyên nhân nào gây giảm thị lực nhiều nhất.

3.2.3. Phân bố tổn thương võng mạc theo tuổi Bàng 3.5. Phân bố tổn thướng vông mạc theo tuổi

\begin{tabular}{|c|c|c|c|c|c|c|}
\hline \multirow[t]{2}{*}{ Tổn thương } & \multicolumn{2}{|c|}{ Không $(n=93)$} & \multicolumn{2}{|c|}{ Có TTVM $(n=80)$} & \multirow{2}{*}{$\begin{array}{c}\text { Tỷ lệ theo } \\
\text { tuổi }\end{array}$} & \multirow[b]{2}{*}{ p } \\
\hline & SL & $\%$ & SL & $\%$ & & \\
\hline$\leq 50$ & 33 & 17,1 & 13 & 16,25 & 16,8 & \multirow{4}{*}{$<0,05$} \\
\hline $51-60$ & 55 & 28,5 & 17 & 21,25 & 26,4 & \\
\hline $61-70$ & 67 & 34,7 & 30 & 37,5 & 35,5 & \\
\hline$>70$ & 38 & 19,7 & 20 & 25 & 21,3 & \\
\hline Tống & 193 & 100 & 80 & 100 & 100 & \\
\hline
\end{tabular}

Trong số 80 bệnh nhân có bệnh võng mạc ĐTĐ, tỷ lệ bệnh nhân gặ̆ nhiều nhất là ở độ tuổi 6170 tuổi chiếm 37,5\%, bệnh nhân ở độ tuổi $51-60$ và > 70 tuổi gặp với tỷ lệ $21,25 \%$ và $25 \%$, gặp ít nhất là ở độ tuổi < 50 tuổi với tỷ lệ 16,25\%. Trong số 193 bệnh nhân không có bệnh, độ tuổi gặp nhiều nhất là từ $51-70$ tuổi, nhóm có độ tuổi < 50 và > 70 tuổi gặp với tỷ lệ $17,1 \%$ và $19,7 \%$. Khác biệt có ý nghĩa thống kê với $\mathrm{p}<0,05$.

3.2.4. Phân bố tổn thương võng mạc theo tỷ lệ HbA1c

Bảng 3.6. Phân bố tổn thương vông mạc theo tỷ lệ HbA1c

\begin{tabular}{|c|c|c|c|c|c|c|c|}
\hline \multirow{2}{*}{ HbA1C(\%) } & \multicolumn{2}{|c|}{ Không (n=193) } & \multicolumn{2}{|c|}{ Chưa TŚ $(n=70)$} & \multicolumn{2}{|c|}{ Tăng $\sinh (n=10)$} & \multirow[b]{2}{*}{$\mathbf{P}$} \\
\hline & $\mathbf{S L}$ & $\%$ & SL & $\%$ & $\mathbf{S L}$ & $\%$ & \\
\hline$\leq 7,0$ & 112 & 58,0 & 20 & 28,6 & 1 & 10,0 & \\
\hline $7,1-10$ & 68 & 35,2 & 35 & 50,0 & 7 & 70,0 & $<0$ \\
\hline$>10$ & 13 & 6,7 & 15 & 21,4 & 2 & 20,0 & \\
\hline
\end{tabular}


Trong nhóm không có tổn thương võng mạc, tỷ lệ bệnh nhân có tỷ lệ HbA1C dưới $7 \%$ gặp nhiều nhất, chiếm $58,8 \%$, thấp nhất là nhóm có $\mathrm{HbA} 1 \mathrm{C}>10 \%$, chiếm $6,7 \%$. Trong nhóm có tổn thương võng mạc, tỷ lệ bệnh nhân có $\mathrm{HbA1C} \leq$ $7,0 \%$ thấp hơn nhóm không có tổn thương. Tỷ lệ gặp nhiều nhất là nhóm có $\mathrm{HbA1C}$ từ $7-10 \%$. Nhóm có $\mathrm{HbA} 1 \mathrm{C}>10 \%$ lại cao hơn hẳn nhóm không có tổn thương với tỷ lệ $20 \%$.

Có mối liên quan chặt chẽ giữa nồng độ $\mathrm{HbA} 1 \mathrm{C}$ với tình trạng tổn thương võng mạc với $p<0,05$.

Kết quả này có thể là do những bệnh nhân trong nhóm nghiên cứu không chỉ được kiểm soát đường huyết tại bệnh viện Đa Khoa Khu
Vực Phúc Yên mà còn được điều trị tại các trung tâm y tế lân cận, do đó mức độ kiểm soát đường huyết không đồng đều. Tại các trung tâm y tế cũng chưa được trang bị máy xét nghiệm đo nồng độ $\mathrm{HbA} 1 \mathrm{C}$, việc kiểm soát đường huyết chủ yễu dựa vào đo đường máu tĩnh mạch, do đó việc kiểm soát đường huyết chưa được đánh giá đầy đủ.

Đặc điểm về mức độ kiểm soát đường huyết trong nhóm nghiên cứu của chúng tôi tương đồng với nghiên cứu của các tác giả Trần Minh Tiên ${ }^{5}$ (2006), và tác giả Nguyễn Thế Vinh ${ }^{7}$ (2015). Như vậy việc kiểm tra định kỳ chỉ số HbA1c có ý nghĩa trong ngăn ngừa biến chứng võng mạc.

\subsubsection{Tổn thương vông mạc ĐTÐ và thời gian mắc bênh ĐTÐ.}

\section{Bảng 3.7. Tổn thương vông mạc ĐTÐ và thời gian mắc bệh ĐTÐ}

\begin{tabular}{|c|c|c|c|c|c|c|c|}
\hline TTVM & \multicolumn{2}{|c|}{ Không TT(n=193) } & \multicolumn{2}{|c|}{ Chưa tăng $\sinh (n=69)$} & \multicolumn{2}{|c|}{ Tăng $\sinh (n=11)$} & \multirow[b]{2}{*}{$\mathbf{p}$} \\
\hline Thời gian & $\mathbf{S L}$ & $\%$ & $\mathbf{S L}$ & $\%$ & $\mathbf{S L}$ & $\%$ & \\
\hline$<5$ năm & 129 & 66,8 & 30 & 43,5 & 1 & 9,1 & \\
\hline $5-10$ năm & 48 & 24,9 & 24 & 34,8 & 5 & 45,5 & $<$ \\
\hline 11- 15 năm & 10 & 5,2 & 8 & 11,6 & 1 & 9,1 & 0,001 \\
\hline$>15$ năm & 6 & 3,1 & 7 & 10,1 & 4 & 36,4 & \\
\hline
\end{tabular}

Trong nhóm bệnh võng mạc ĐTĐ giai đoạn chưa tăng sinh, số bênh nhân có thời gian mắc bệnh $Đ T Ð<5$ năm chiếm tỷ lệ cao nhất $(43,8 \%)$, sau đó là nhóm có thời gian mắc từ 5-10 năm là $34,8 \%, 2$ nhóm từ 11-15 năm và > 15 năm chiếm tỷ lệ tương ứng là $11,6 \%$ và $10,1 \%$. Trong nhóm bệnh võng mạc ĐTÐ giai đoạn tăng sinh, tỷ lệ gặp nhiều nhất ở 2 nhóm mắc bệnh từ $5-10$ năm và > 15 năm chiếm tỷ lệ $45,5 \%$ và $36,4 \%$, 2 nhóm còn lại cùng chiếm tỷ lệ $9,1 \%$. Trong nhóm không mắc bệnh võng mạc ĐTĐ, tỷ lê găp nhiều nhất ở nhóm có thời gian mắc bênh $<5$ năm chiếm tỷ lệ $66,8 \%$, các nhóm khác có tỷ lệ giảm dần. Tỷ lể bệnh nhân mắc bệnh võng mac ĐTĐ nhiều nhất gặp ở nhóm có thời gian mắc ĐTĐ từ 5-10 năm. Đăc biệt, trong nhóm có thời gian mắc ĐTĐ > 15 năm, tỷ lệ bệnh nhân mắc bệnh võng mạc ĐTĐ giai đoạn tăng sinh cao hơn nhiều so với 2 nhóm còn lại. Khác biêt rất có ý nghĩa thống kê với $p<0,001$, cho thấy mối liên quan chặt chẽ giữa thời gian mắc bệnh ĐTÐ với biến chứng võng mạc ĐTĐ.

Kết quả nghiên cứu của chúng tôi phù hợp với kết quả mà tác giả Klein ${ }^{3}$ đưa ra trong nghiên cứu Wisconsin 1984. Theo nghiên cứu này, tỷ lệ bệnh nhân có tổn thương võng mạc do đái tháo đường thay đổi từ $17 \%$ đến $97,5 \%$ trong nhóm mắc bênh đái tháo đường dưới 5 năm tới nhóm mắc bệnh trên 15 năm. So với kết quả trên, tỷ lệ bệnh nhân có tổn thương võng mạc trong nhóm mắc bệnh ĐTĐ của chúng tôi tương đương với tỷ lệ mà tác giả Klein đưa ra, tuy nhiên tỳ lệ bệnh nhân có tổn thương võng mac ở nhóm mắc bênh ĐTĐ > 15 năm lại có xu hướng thấp hơn. Có thể do nghiên cứu của chúng tôi tiến hành sau nghiên cứu Wisconsin nhiều năm (23 năm), việc điều trị và quản lý bênh nhân ĐTĐ có nhiều tiến bộ, do đó tỷ lệ bểnh nhân có biến chứng do bệnh ĐTĐ cũng giảm so với trước đây.

\section{KẾT LUÂ̂N}

Trong số 546 mắt của 273 bệnh nhân ĐTĐ thuộc nhóm nghiên cứu, có 139 mắt mắc bệnh võng mạc ĐTÐ ở các giai đoạn khác nhau $(25,5 \%)$ và 33 mắt phù $\mathrm{HĐ}(6 \%)$. Như vậy tỷ lệ mắc bệnh khá cao trong quần thể bệnh nhân ĐTĐ. Trong khi đó, đáng chú ý có mối liên quan chặt chẽ giữa thời gian mắc bệnh ĐTÐ và khả năng kiểm soát đường máu với tỷ lệ mắc bệnh. Vì vậy cần phải có chiến lược khám sàng lọc bênh võng mạc ĐTĐ bên cạnh việc điều trị bệnh nhân ĐTĐ tại địa phương trong thời gian tới.

\section{TÀI LIẸU THAM KHẢO}

1. The Vision loss Expert Group of the Global Burden of Disease Study. Global estimates on the number of people blind or visually impaired by diabetic retinopathy: a meta-analysis from 1990 to 2010. Diabetes Care, 2016;39, 1643-1649.

2. Fong D. S., Aiello L., Gardner T. W. et al. Diabetic retinopathy. Diabetes Care, 2003; 26(1), 226-229.

3. Klein R., Knudtson M. D., Lee K. E. et al. The Wisconsin Epidemiologic Study of Diabetic Retinopathy: XXII the twenty-five-year progression 
of retinopathy in persons with type 1 diabetes. Ophthalmology, 2008; 115(11), 1859-1868.

4. Lee $\mathbf{R}$, Wong TY, Sabanayagam C. Epidemiology of diabetic retinopathy, diabetic macular edema and related vision loss. Eye and vision. 2015;2(1):1-25.

5. Trân Minh Tiến, Nghiên cứu một số đặc điểm dich tễ hoc và lâm sàng bệnh võng mac đái tháo đường tại bệnh viện, Luận văn tốt nghiệp bác sỹ chuyên khoa cấp II, Trường Đai học Y Hà nội; 2006

6. Hoàng Thị Phúc và cs. Úng dụng các phương pháp phát hiện sớm bênh lý võng mac ở bênh nhân đái tháo đường và các phương pháp điều trị. Đề tài nghiên cứu khoa học cấp bộ, Bộ Y tế; 2012

7. Nguyễn Thế Vinh, Đánh gia tổn thương hoàng điểm trên bệnh nhân đái tháo đường điều trị tại Viện lão khoà trung ương và Bệnh viện Bạch maí, Luận văn tốt nghiệp Thạc sỹ y học; 2015

\section{ĐÁNH GIÁ CHI PHÍ - HIỆU QUẢ CỦA INSULIN GLARGINE VÀ DETEMIR TRÊN BỆNH NHÂN ĐÎ̀̀U TRI ĐÁI THÁO ĐƯờ'NG TÍP 2 TẠI VIỆT NAM}

\section{TÓM TẮT}

Đặt vấn đề: Đái tháo đường (ĐTĐ) típ 2 đang gia tăng về tỉ lệ mắc bệnh, ảnh hưởng lớn tới sức khỏe, chất lượng cuộc sống người bệnh và đặt gánh nặng kinh tế cho hể thống y tế. Sử dưng insulin nền tác dụng kéo dài là một trong nhiều phác đồ điêu trị ĐTĐ tại Viêt Nam. Mục tiêu của nghiên cứu là so sánh chi phí - hiệu quả giữa hai thuốc insulin analog tác dụng kéo dài glargine và detemir trong điêu tri ĐTĐ típ 2 ỏ Việt Nam. Phương pháp nghiên cứu: Phân tích chi phí- hiệu quả sử dưng mô hình cây quyết định với các thông số đâu vào dựa trên tổng quan y văn. Phân tích dựa trên quan điểm của cơ quan chi trả bảo hiểm. Mô hình ước tính chi phí và chất lượng cuộc sống của bệnh nhân sử dụng insulin glargine hoăc detemir và các biến chứng đái tháo đường bao gồm: đột quy. nhồi máu cơ tim, bệnh mạch máu ngoại biên và hạ đường huyết mức độ nghiêm trọng. Xác suất dịch chuyển, chi phí và thỏa dụng của bệnh nhân được hiệu chỉnh dựa trên \%HbAic giảm trung bình khi sử dụng thuốc và khả năng kiểm soát $\mathrm{HbA} 1 \mathrm{c}(\leq 7 \%)$ của mối insulin. Phân tích độ nhạy một chiều được áp dụng trên các thông số đầu vào nhử liều dùng insulin, tỉ lệ mắc biến chứng, tỉ lệ giảm nguy cơ và chi phí điều trị biến chứng. Kết quả: Insulin glargine có chi phí - hiệu quả vượt trội, chi phí tiết kiệm trung bình 1.853.848 VND/bệnh nhân/năm, hiệu quả tính theo thỏa dung gia tắng trung bình 0,0008 QALY/bệnh nhân/nằm. Kết luận: Bằng chứng cho thấy việc sử dụng insulin glargine điều trị ĐTĐ típ 2 trong bối cảnh Việt Nam có thể đem lại chi phí - hiệu quả cho cơ quan chi trả bảo hiểm.

\section{SUMMARY \\ COST-EFFECTIVENESS ASSESSMENT FOR INSULINE GLARGINE AND DETEMIR ON DIABETES MELLITUS TYPE 2 PATIENTS IN VIETNAM}

\footnotetext{
${ }^{1}$ Trường Đại học Y tế công công

2Trường Đại hoc Dước Hà Nội

Chịu trách nhiểm chính: Nguyễn Minh Văn

Email: nmv@huph.edu.vn

Ngày nhân bài: 8.3.2021

Ngày phản biên khoa hoc: 27.4.2021

Ngày duyệt bài: 11.5.2021
}

Background and Objectives: Type 2 diabetes mellitus prevalence and mortality is increasing rapidly in recent years. Analog long-acting basal insulin is one of the most important diabetes treatment regimens in Vietnam. This study was conducted to assess the costeffectiveness of two insulin analogs available in Vietnam: insulin glargine compared to insulin detemir when using for diabetes mellitus type 2 (T2DM) patients in Vietnam, based on published literature. Methods: A decision tree model was developed to assess the associated cost and utility when a patient uses insulin glargine or detemir and their risks of T2DM complications: Myocardial infarction, Stroke, Peripheral diseases and Severe hypoglycemia. Transitional probabilities, costs and utility are adjusted based on the mean \%HbA1c reduction and probability of controlling blood glucose $(\% \mathrm{HbA} 1 \mathrm{c} \leq 7 \%)$ for each insulin. Results: Insulin glargine is cost-effective compared to insulin detemir, with lower cost (saving $1,853,848 \mathrm{VND} /$ patient/year) and gaining additional utility (0.008 QALY/patient/year). Conclusions: The study provides the evidence for insulin glargine's costeffectiveness when compared to insulin detemir for T2DM treatment in Vietnam.

Keywords: diabetes mellitus type 2, cost effectiveness, insulin glargine, insulin detemir.

\section{I. ĐĂT VẤN ĐỀ}

Đái tháo đường (ĐTĐ) là một trong những bệnh lý không lây nhiễm phổ biến trên thế giới với tỉ lệ mắc bệnh có xu hướng ngày càng gia tăng. Mục tiêu kiểm soát đường huyết ở bệnh nhân ĐTĐ típ 2 được đánh giá bởi nồng độ HbA1c trong máu và tỉ lệ mắc các biến chứng bệnh nhân ĐTĐ típ 2 đã được chứng minh có tương quan với nồng độ $\mathrm{HbA} 1 \mathrm{c}^{1}$. Tại Việt Nam, năm 2015, ước tính có khoảng 3,5 triệu bệnh nhân mắc ĐTĐ và con số này được dự báo sẽ tăng lên 6,1 triệu người vào năm 2040. Bệnh ĐTĐ không chỉ ảnh hưởng tới sức khỏe, tuổi thọ và chất lượng cuộc sống của người bệnh mà còn có gánh nặng kinh tế lớn lên hệ thống y tế. Năm 2017, Bảo hiểm y tế (BHYT) đã chi trả khoảng 435 triệu Đô la Mĩ cho điêuu trị ĐTĐ tại Việt 